\title{
REMOTE SENSING TECHNIQUES IN DISASTER MANAGEMENT: AMYNTEON MINE LANDSLIDES, GREECE
}

\author{
A. Karagianni ${ }^{1, *}$, I. Lazos $^{2}$, A. Chatzipetros ${ }^{2}$ \\ ${ }^{1}$ Aristotle University of Thessaloniki, School of Civil Engineering, Faculty of Engineering, Lab. of Photogrammetry - Remote \\ Sensing, Thessaloniki, Greece - aikateck@ civil.auth.gr \\ ${ }^{2}$ Aristotle University of Thessaloniki, School of Geology, Lab. of Geology and Palaeontology, Thessaloniki, Greece - \\ (ilialazo, ac)@geo.auth.gr
}

KEY WORDS: remote sensing, digital image processing, image interpretation, fault zones, disaster management, landslides

\begin{abstract}
:
Natural or man-made disasters are phenomena that can affect large areas and have many environmental, societal and economic impacts. Landslides are among the major disasters of large scale that may affect the natural environment as well as urban areas, often causing massive destruction, loss of property, or even fatalities worldwide. Developing tools that are effective for disaster management is imperative to monitor and mitigate their effect. Satellite data and remote sensing techniques, combined with geological data and studies can provide valuable information regarding monitoring of natural hazards in general and especially of landslides. This paper concerns the ex ante and ex post study of a complex set of landslides that occurred in the lignite mine of Amynteon in north-western Greece (June 2017), where large masses of Neogene lacustrine and Quaternary fluvial sediments were detached and moved. The study area is located at the transfer zone between the overlapping tips of two large NE-SW trending normal fault zones affecting the overlying sediments: the NW-dipping Anargyri fault and the SE-dipping Vegora fault. The fragmentation caused by these fault zones weakened the material cohesion, which was further degraded by mining activities and hydrogeological factors, leading to the catastrophic event. The landslide occurred in along the south faces of the mine, resulting to extended collapses, destruction of mining machinery, evacuation of the adjacent Anargyri village and a big financial impact that has not yet been determined. Landsat 8 and Sentinel-2 satellite data acquired before and after the event are being used. Digital image processing techniques are applied for change detection. In addition, geological data are being used to provide information about the geological background of the area and landslides vulnerability. Visual interpretation of the area affected by the landslides is also being done, contributing to the overall study.
\end{abstract}

\section{INTRODUCTION}

Natural or man-made disasters are phenomena that can affect large areas and have many environmental, societal and economic impacts (van Westen, 2000). Landslides are among the major disasters of large scale that may affect the natural environment as well as urban areas. The occurrence of destructive landslide phenomena is frequent worldwide, causing radical changes in the wider area, related to geomorphological, environmental, societal and economic factors (Metternicht et al., 2005).

Monitoring landslide activity over extensive areas occurs as an important aspect at the management of natural hazards and risk assessments. Landslide monitoring could be accomplished by several methods (Hervás et al., 2003).

Among the used methods, satellite data and remote sensing techniques can be proven of particular importance as they provide wide coverage of the affected areas, high frequency data and information about non-visible spectral regions (Mantovani et al., 1996; Scaioni et al., 2014; Joyce et al., 2009). Additional geological data can provide information about the geological background of the area contributing in landslide disaster management studies (Scaioni et al., 2014).
This paper concerns a large scale landslide phenomenon that took place in June 10, 2017 in the lignite mine of Amynteon, Western Macedonia, Greece, leading to the destruction of a large part of the mine, cancelation of mining activities, partial destruction and evacuation of the adjacent Anargyri village and multiple socio-economic impacts. Landsat 8 and Sentinel-2 satellite data acquired before and after the event are being used. Digital image processing techniques are applied for change detection and visual interpretation of the area affected by the landslides is also being done. In addition, an overview of the geological structure and the tectonic setting of the active faults of the area, as well as the landslide type and its triggering factors are presented.

\section{STUDY AREA}

Study area is located in the north-western part Greece, region of Western Macedonia, in medium-high altitude $(600 \mathrm{~m})$ and concerns the lignite mine of Amynteon. The mine is located between lakes Vegoritis and Chimaditis, close to the town of Amynteon. The smaller village of Anargyri is located on the southwest side of the mine (Figure 1).

Corresponding author 


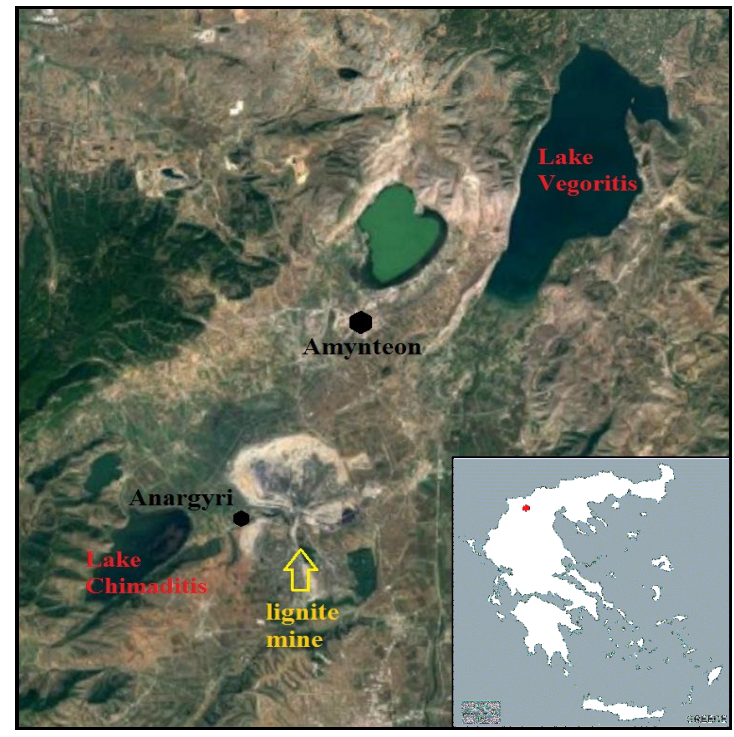

Figure 1. Location of the study area in Greece (red dot) and satellite image of the mine from Google Earth (https://maps.google.com)

\section{GEOLOGICAL AND STRUCTURAL SETTING}

\subsection{Geological setting}

The bedrock of the broader area is comprised mainly of Pelagonian geological zone and, covering a much smaller area, Subpelagonian rocks. In general terms, Palaeozoic metamorphic rocks are overlain either stratigraphically or tectonically by younger Mesozoic and Tertiary rocks (Mountrakis, 1986). The bedrock is uncomformably covered in places by post-alpine sedimentary formations, while Upper Quaternary deposits (mainly alluvium and scree) cover locally both of them. The Pelagonian bedrock is mainly structured in four distinct units (Mountrakis, 1986; Pavlides and Mountrakis, 1987): a) Palaeozoic crystalline rocks, including granite intrusions and Permian-Triassic metaclastic sequences, b) Triassic-Jurassic carbonates, which constitute the main part of the bedrock in the study area, c) ophiolites and associated sediments, overthrusting Pelagonian zone and d) Middle-Late Cretaceous transgressive sediments. Most of the study area is covered by mainly lacustrine Middle Pliocene - Lower Pleistocene sediments. The Pliocene formation comprises of three main horizons: the lower one is dominated by conglomerate, containing ophiolitic clasts, red clay and marls. A middle horizon comprises of fine-grained sediments, mainly white marl, with thin lignite-bearing layers. The uppermost horizon contains alternations of white marl and marly limestone with occasional sandy layers. The total thickness of the Pliocene deposits is more than $700 \mathrm{~m}$ at the central part of the basin. The Lower Pleistocene sequence is rather cohesive and consists of red clays with gravel parts at its lower part and red clay and breccia at its upper one (Pavlides and Mountrakis, 1987).

\subsection{Structural setting}

$\mathrm{T}$ The area of NW Greece has been subjected to several deformations, which caused continuous geomorphological changes and a variety of tectonic structures (active or not). Successive deformation phases affected in various ways the geotectonic evolution of the area, forming its current structure (Kilias and Mountrakis, 1989). The first major deformation phase is associated to the thrusting of Axios (Vardar) and
Subpelagonian ophiolites. They overthrust the Pelagonian carbonates and are associated with the destruction of the Axios and Subpelagonian-Pindos oceans. This phase is imprinted on the schistosity and folding and is characterized by abundant ophiolitic mélange. The Upper Cretaceous - Upper Eocene compressional phase formed NW - SE trending folds and thrusts. This imbrication caused widespread inversions, especially along the western Pelagonian margin. The major folding resulted in the formation of NW - SE trending anticline and syncline structures.

An ENE - WSW trending extensional event during the Lower Oligocene formed the molassic Mesohellenic Trench. The detachment faults of this phase affected the ophiolite masses under semi-ductile conditions, causing their displacement to approximately their current location. The 40-km-wide Mesohellenic Trench is developed in a NNW - SSE direction, transversely to the direction of Lower Oligocene extension, constituting the most recent and extensive molassic trench of Greece, while the sedimentation went on from Oligocene to Upper Miocene. During the Middle - Upper Miocene, an E - W compressional phase caused the formation of $\mathrm{N}-\mathrm{S}$ trending ophiolite imbrications, as well as strike-slip faults of WNWESE strike. A significant number of them were reactivated as normal faults during the subsequent extensional neotectonic phases. The compressional deformation was completed during the Upper Miocene by the last NNE-SSW trending phase. This phase formed E-W reverse faults in the ophiolitic masses and reactivated of the inherited strike-slip faults.

\subsection{Neotectonic setting}

Two main neotectonic extensional phases affected the broader NW Greece area (Pavlides, 1985; Pavlides and Mountrakis, 1987). The first one, during Upper Miocene - Pliocene, created or reactivated NW - SE trending normal faults, which formed large grabens of the same direction. A constant NE - SW directed extensional stress field affected the entire interior Aegean region. The last deformation phase during the Quaternary is still active. This NNW - SSE trending extension caused the formation or reactivation of significant NE-SW to E$\mathrm{W}$ striking normal faults. They caused the fragmentation of the large grabens into smaller transverse sub-basins. This extensional phase is currently active and its faults played the most important role in the neotectonic evolution of the area. Several of these NE-SW to ESE-WNW striking faults have been active during the Neogene-Quaternary and are located within the large basins of the area (Florina, AmynteonPtolemais and Kozani ones). One of the most important faults in the area is the Aliakmon one, a segment of which was activated during the May $13^{\text {th }}, 1995$ Kozani-Grevena Mw 6.6 earthquake (Pavlides et al., 1995; Chatzipetros, 1998).

\subsection{Active faults of the study area}

The broader Ptolemais basin, where the lignite mine of Amynteon is located, is characterized by six major active fault zones (Figure 2). They are Komnini-Asvestopetra (possibly extended to Pyrgi village), Emporion-Perdika, Anargyri (or Chimaditida-Anargyri), Perea-Maniaki, Vegora (or VegoritidaAgios Panteleimon) and Nymfeon-Xino Nero-Petres Lake (Pavlides, 1985). The Amynteon mine landslide is associated to Anargyri and Vegora active faults. Nevertheless, a multitude of secondary faults also affect the area of the mine and might have contributed to the weakening of the rock/soil mass (see Tzampoglou and Loupasakis, in press, and references therein). 


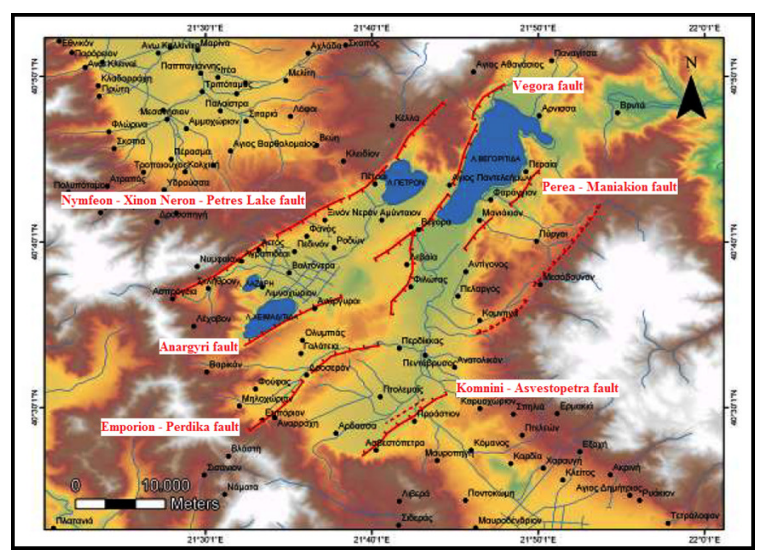

Figure 2. Simplified structural map of the study area (modified from Pavlides, 1985)

\subsubsection{Anargyri fault}

Anargyri fault is one of the major faults of Amynteon-Ptolemais basin and defines the southern shore of Chimaditida Lake (Pavlides, 1985). It is of N60E strike and dips to the NW. It forms the Chimaditida Lake graben, which is the most recent (Quaternary) graben of the basin. Based on drilling data from the lignite-bearing sediments, the estimated fault throw is 130 $\mathrm{m}$. The Anargyri fault affects the entire Pliocene-Quaternary sequence.

\subsubsection{Vegora fault}

Vegora fault is a major normal fault along the western shore of Vegoritida Lake, with a NE - SW strike (between $30^{\circ}$ and $40^{\circ}$ ), while the estimated dip angle is $60^{\circ} \mathrm{SE}$ (Pavlides, 1985). The total length of Vegora fault is $20 \mathrm{~km}$, and it deforms the Mesozoic Pelagonian carbonates, forming the Vegoritida Lake graben. A SW extension of this fault zone extends into the Pliocene and Quaternary sediments of Ptolemais basin, while the fault throw is estimated between 200 and $500 \mathrm{~m}$. It is also considered an active fault, as it deforms very recent scree that overlies the fault slickenside.

\section{THE AMYNTEON MINE LANDSLIDES}

Landslides are some of the most important destructive phenomena and are caused by both natural and man-made factors. Landslides are classified into several types, the main ones being a) rotational, b) translational, c) block slide, d) rockfall, e) toppling and f) creep. The Amynteon lignite mine landslide shows characteristics of a rotational landslide. According to USGS (https://pubs.usgs.gov), rotational landslide is a slide in which the surface of rupture is curved concavely upward and the slide movement is roughly rotational about an axis that is parallel to the ground surface and transverse across the slide. Furthermore, this type of landslide is observed mainly into soil masses, while other landslide types (block slide, rockfall and topple) are common in cohesive rock formations.

The exact failure factors have not been determined yet and are subject to ongoing modelling (e.g. Tzampoglou and Loupasakis, 2017a, b, in press; Dimitrakopoulos and Koumantakis, 2017), as well as investigation by expert panels appointed by the Ministry of Infrastructure, Transport and Networks and the owner of the mine (Public Power Company S.A.). It is possible that the Plio-Pleistocene sedimentary sequence in Amynteon mine acted as a soil mass, due to the intense fragmentation caused by extensive faulting and jointing associated to the transfer zone between Anargyri and Vegora fault zones. These faults affected the lignite bearing formations, causing poor cohesion and leading to the formation of a multifragmented mass. Furthermore, it is possible that human factors affected the initiation of the landslide. The deep excavation at the foot of the mining fronts and the simultaneous deposition of material at the mine's upper part may have charged the upper excavation area, while the stability at the lower part was reduced. Initial signs of failure (e.g. creep, surface ruptures, etc.) caused halting of mining activity at this sector and removal of machinery. Finally, a few days before the main landslide a rather extreme rain event was recorded (36.2 $\mathrm{mm}$ of precipitation) during a normally dry period (http://meteosearch.meteo.gr/data/amyntaio/2017-06.txt) (Figure 3).

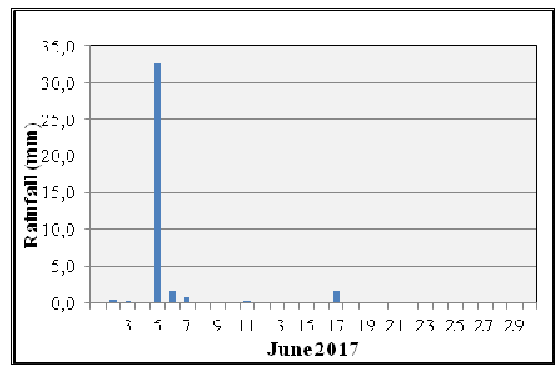

Figure 3. Rainfall during June 2017

The landslide effects covered a large area and caused damages in the order of several hundreds of millions of Euros, due to loss of exploitable lignite deposits, destruction of mining machinery and equipment, halting of works and significant damages to the nearby Anargyri village, a large part of which was preventively evacuated (Figures 4 and 5). Compensation of properties and public infrastructure damaged during the landslide will also add further to the total cost.

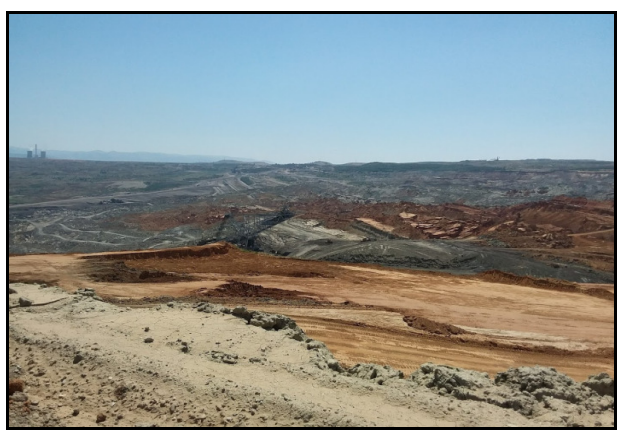

Figure 4. General view of the June 10, 2017 Amynteon mine landslide

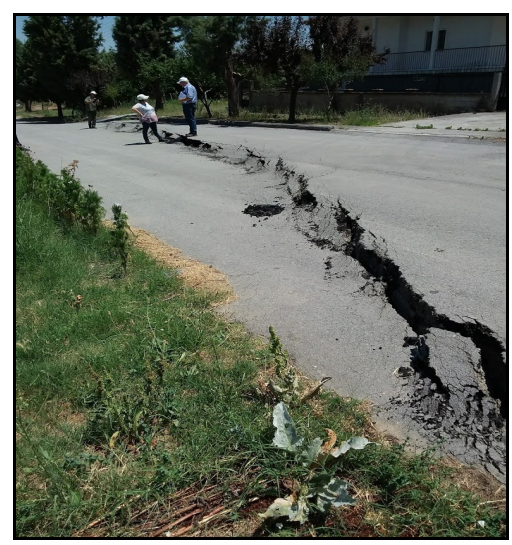

Figure 5. Ground rupture at Anargyri village due to the landslide 


\section{SATELLITE DATA}

The data employed for this study concern Landsat 8 and Sentinel-2 satellite imagery acquired before and after the catastrophic event, providing the ability to detect the landslide and monitor the affected area, highlighting also the changes.

\subsection{Landsat 8 satellite data}

Landsat 8 was launched on February 11, 2013 and carries two instruments: The Operational Land Imager (OLI) sensor and the Thermal Infrared Sensor (TIRS). These sensors both provide improved signal-to-noise (SNR) radiometric performance, quantized over a 12-bit dynamic range (4096 potential grey levels in an image compared with only 256 grey levels in previous 8-bit instruments). Improved signal to noise performance enables better characterization of land cover state and condition (http://landsat.usgs.gov/landsat8.php).

Satellite data acquired from Landsat consist of eleven spectral bands with a spatial resolution of 30 meters for Bands 1 to 7 and 9. The resolution for Band 8 (panchromatic) is $15 \mathrm{~m}$ and for Bands 10, 11(thermal bands) is $100 \mathrm{~m}$. Among the eleven spectral bands, Landsat 8 includes one band that measures the near infrared (Band 5-NIR) and two bands that cover different slices of the shortwave infrared (Bands 6 and 7-SWIR).

Landsat 8 satellite data could be a useful tool for monitoring and analysing the territory, as their spectral capabilities give the opportunity to identify the extent of the landslide and provide additional information about the landslide location and the affected area in general.

The image data that have been used in this study were downloaded free of charge from U.S. Geological Survey (USGS: http://earthexplorer.usgs.gov). They were acquired at 2017-05-02 (path: 185, row: 32) and 2017-06-26 (path: 184, row: 32) before and after the landslide event respectively, with level processing 1T - Standard Terrain Correction (systematic radiometric and geometric accuracy) and projection information: UTM, zone 34, spheroid \& datum WGS 84 . The images have excellent quality (image quality: 9 ).

\subsection{Sentinel-2 satellite data}

Sentinel-2 mission consists of two polar-orbiting satellites (Sentinel-2A and Sentinel-2B) providing high-resolution optical imagery for land monitoring. The full mission specification of the twin satellites flying in the same orbit but phased at $180^{\circ}$, is designed to give a high revisit frequency of 5 days at the Equator. Among the mission objectives is the disaster relief support and change detection maps (https://sentinel.esa.int/web/sentinel/missions/sentinel-2).

Sentinel-2A was launched on June 23, 2015 while Sentinel-2B on March 07, 2017. Both satellites are equipped with the MSI (Multispectral Imager) instrument that offers high-resolution optical images. Sentinel-2 mission, as Landsat 8 , is provided on board with an optical-multispectral high resolution sensor that operates on/covering 13 different bands: four visible and nearinfrared bands with a spatial resolution of $10 \mathrm{~m}$ (bands 2, 3, 4, 8), six red edge and shortwave infrared bands with a spatial resolution of $20 \mathrm{~m}$ (bands $5,6,7,8 \mathrm{~A}, 11,12$ ) and three atmospheric correction bands with a spatial resolution of $60 \mathrm{~m}$ (bands 1, 9, 10). Sentinel data products are available to all users and can be accessed free of charge (free, full and open data policy adopted for the Copernicus programme) through the Copernicus Open Access Hub (https://scihub.copernicus.eu).

The image data that have been used in this study derive from Sentinel-2A (S2A_MSIL2A) and were acquired at 2017-06-01 and 2017-06-21 respectively with level processing 2A. The Level-2A products provide Bottom of Atmosphere (BOA) reflectance images derived from the associated Level-1C products. Each Level-2A product is composed of 100x $100 \mathrm{~km}^{2}$ tiles in cartographic geometry (UTM/WGS84 projection).

\section{DIGITAL IMAGE PROCESSING}

To detect and delineate the area affected by the landslide, several methods can be applied.

Initially, different color composites can be used to highlight several features in the landscape and reveal the bare ground or vegetation allowing the interpreter to detect the presence of landslides. Spectral bands capture energy in different parts of the electromagnetic spectrum. Using different band combinations certain features will contrast greatly with their surroundings, enabling better delineation (Scaioni et al., 2014).

Further digital image processing techniques (spectral enhancement, pan-sharpening, image, etc.) can be applied for change detection and direct landslide monitoring (Hervás et al., 2003; Joyce et al., 2009; Scaioni et al., 2014). Visual interpretation of images (before or/and after digital processing) taken at different times can also contribute to the qualitative analysis of change detection (Scaioni et al., 2014) and is being done on the base of geometric (shape, size, etc.) and radiometric (tone-color, texture) characteristics. Optical data can provide good results due to spatial resolution and sensor look angle (although misclassification in other areas of bare ground may appear) (Joyce et al., 2009; van Westen, 2000).

The software that was used for the digital processing of the satellite imagery is ERDAS Imagine 2011 and SNAP (Sentinel Application Platform) freely distributed by ESA.

\subsection{Landsat 8 image processing}

Digital processing of Landsat 8 data included layerstacking of the downloaded data, subsetting the scene to the study area, spectral enhancement performing principal components analysis (PCA) and image fusion (pan-sharpening) using Wavelet transform.

As a first step, various color composites can be used to visualize the information in the bands of the acquired images. In this study, the band combinations that were considered the most effective for a qualitative approach of the landslide detection were the following: the Natural Color Composite 4-3-2 (Red: Band 4, Green: Band 3, Blue: Band 2) and the Color Composite 6-3-2 (Red: SWIR1-Band 6, Green: Band 3, Blue: Band 2). These band combinations were applied at the images acquired before (02-05-2017) and after (26-06-2017) the event and were visually compared.

In the Natural Color Composite 4-3-2 (Figure 6) ground features appear in colors similar to their appearance to the human visual system. The landslide area is detected in the left part of the mine and the slope deformations are visible. In the Color Composite 6-3-2 (Figure 7), the landslide area is also detected and clearly highlighted, as the shortwave infrared band 
(SWIR1) that were used in this combination is suitable for discerning differences in bare earth, indicating wet and dry areas in a scene.
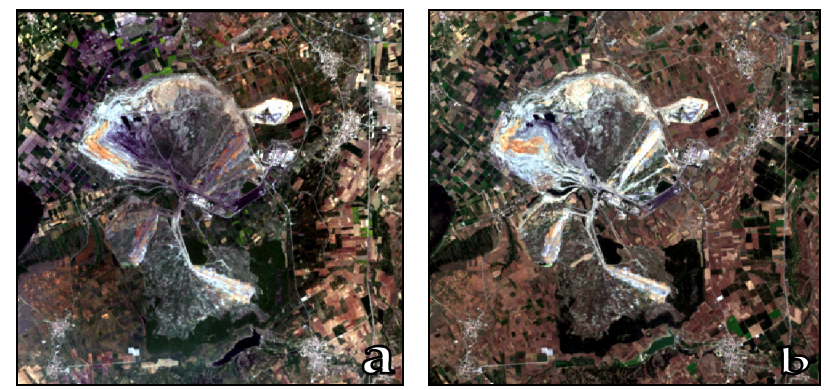

Figure 6. Study area in Natural Color Composite (4-3-2) before (a) and after (b) the landslide
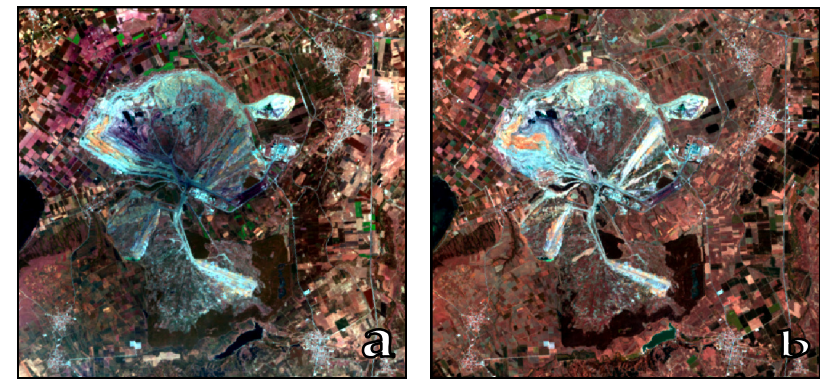

Figure 7. Study area in Color Composite (6-3-2) before (a) and after (b) the landslide

Further digital processing concerned spectral enhancement of the satellite images, applying principal components analysis (PCA).This statistical method of data compression allows redundant data to be compacted into fewer bands. Dimensionality of the data set is reduced by projecting the data along new non-correlated axes. The bands of PCA data (principal components-PCs), are non-correlated and independent, therefore are often more interpretable than the source data (ERDAS Field Guide, 2013; Deng et al., 2008). Although there are $\mathrm{n}$ output bands in a PCA, the first few bands account for a high proportion of the variance in the data. This image enhancement technique is useful for compressing data into fewer bands and can be used to give satisfactory results in change detection analysis, as in several applications appears to be better than classification comparison approach for change detection (Gupta et al., 2013).

There are several ways to apply PC transformation for change detection (Deng et al., 2008). In this study, to detect changes that appeared after the landslide, Landsat 8 images of two different times were both transformed into new PCA images applying PC transformation and were compared visually (Figure 8). Most of the variance of the dataset is found on the first components. Therefore, the first three images are presented (3 principal components: PC1, PC2, PC3) as they provide most of the information contained within the dataset. The results were evaluated visually.

Areas affected by the landslide are evident in all three components. In PC1 pair of images the landslide area appears in lighter shades of grey while built up areas and water regions are also highlighted. In PC2 pair of images landslide area appears in darker shades and vegetation regions are discernible. In PC3 pair of images the 'boundaries' of the lignite mine are delineated and especially the landslide area in the left part of the mine (lighter shades of grey) where a shape disturbance is detected.
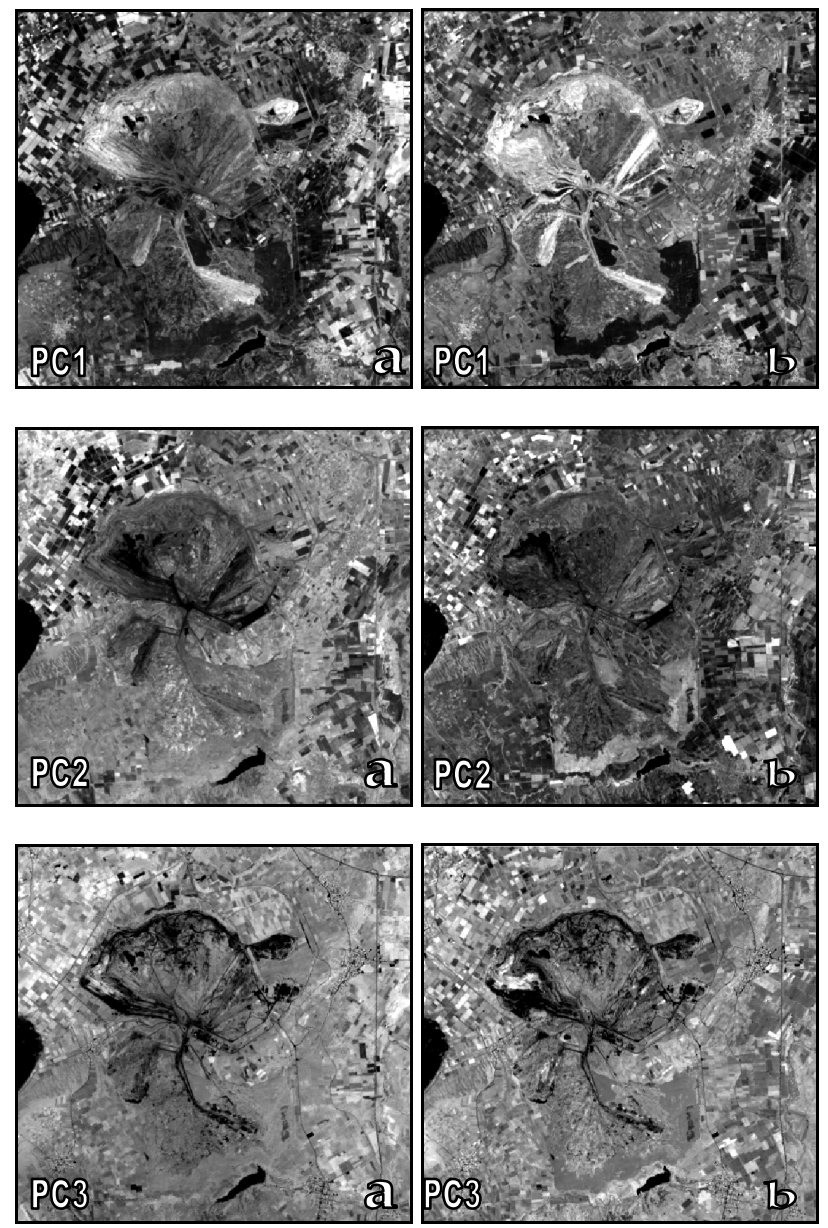

Figure 8. PCA images of the study area before (a) and after (b) the landslide

To exploit the panchromatic band of Landsat 8 (spatial resolution: $15 \mathrm{~m}$ ) image fusion (pan-sharpening) was performed in order to delineate the landslide area in more detail. Various methods have been developed for image fusion. In this study, Discrete Wavelet transform (DWT) was chosen as in several cases seem to preserve better the spectral characteristics of the original multispectral image and can be more effective for further digital processing (Karagianni and Lazaridou, 2017; Gungor and Shan, 2004).

Wavelet methods belong in the broader category of Multiple Resolution Analysis (MRA) methods. In wavelet fusion, a high resolution panchromatic image is first decomposed into a set of low resolution panchromatic images using corresponding wavelet coefficients (spatial details) for each level. Individual bands of the multispectral image then replace the low resolution panchromatic image at the resolution level of the original multispectral image. The high resolution spatial detail is injected into each multispectral band by performing a reverse wavelet transform on each multispectral band using the corresponding wavelet coefficients (Zhang, 2004).

The pansharpened images are presented in Figure 9 focusing in the affected area (left part of the mine) and are evaluated visually as well as quantitatively. 

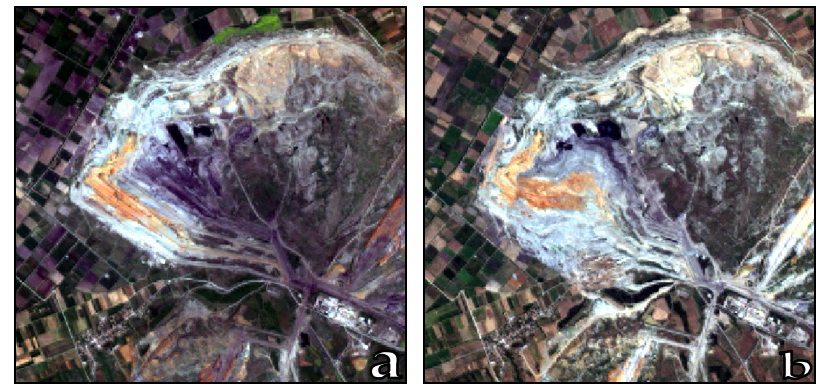

Figure 9. Pansharpened images of the study area in Natural Color Composite 4-3-2) before (a) and after (b) the landslide

As is presented in Figure 9, the spatial resolution of the images after pan-sharpening is improved and the landslide area is distinguished in more detail. In addition, there is a minimum color distortion regarding the original multispectral images. Therefore, the resulted images are suitable for change detection as spectral information is maintained while at the same time spatial resolution is increased.

In order to evaluate quantitatively the pansharpened images for both dates, the correlation coefficients among the Landsat 8 multispectral bands before and after pan-sharpening were calculated. The results are presented in Table 1, indicatively for bands 2,3,4. An acceptable fusion approach should not present considerable changes in the correlation of the corresponding bands (Gungor and Shan, 2004). As shown in Table 1, the correlation among all bands is subject to minor changes after applying Wavelet transform. In addition, high spectral value preservation is observed, as values are close to +1 .

\begin{tabular}{|c|c|c|c|c|}
\hline \multicolumn{2}{|c|}{ 02-05-2017 } & Band 2 & Band 3 & Band 4 \\
\hline \multirow{2}{*}{ Band 2 } & before & 1 & 0.964 & 0.878 \\
\cline { 2 - 5 } & after & 1 & 0.963 & 0.877 \\
\hline \multirow{2}{*}{ Band 3 } & before & 0.964 & 1 & 0.940 \\
& after & 0.963 & 1 & 0.939 \\
\hline \multirow{2}{*}{ Band 4 } & before & 0.878 & 0.940 & 1 \\
\cline { 2 - 5 } & after & 0.877 & 0.939 & 1 \\
\hline \multirow{2}{*}{ 26-06-2017 } & Band 2 & Band 3 & Band 4 \\
\hline \multirow{2}{*}{ Band 2 } & before & 1 & 0.974 & 0.899 \\
\cline { 2 - 5 } Band 3 & after & 1 & 0.973 & 0.898 \\
\cline { 2 - 5 } & before & 0.974 & 1 & 0.945 \\
\hline \multirow{2}{*}{ Band 4 } & befter & 0.973 & 1 & 0.944 \\
\hline \multirow{2}{*}{ Cofore } & 0.899 & 0.945 & 1 \\
\hline
\end{tabular}

Table 1. Correlation coefficients among the Landsat 8 multispectral bands before and after pan-sharpening (for both dates and indicatively for bands $2,3,4$ )

\subsection{Sentinel-2A image processing}

Digital processing of Sentinel-2A data included resembling at $10 \mathrm{~m}$, layerstacking of the downloaded data, subsetting the scene to the study area and image algebra technique implementation (image difference) to detect the changes.

Figure 10 presents the study area before and after the landslide in Natural Color Composite (4-3-2), as well as a second pair of subsets that focuses on the left area of the mine where the landslide occurred (red rectangle in the first pair of images).
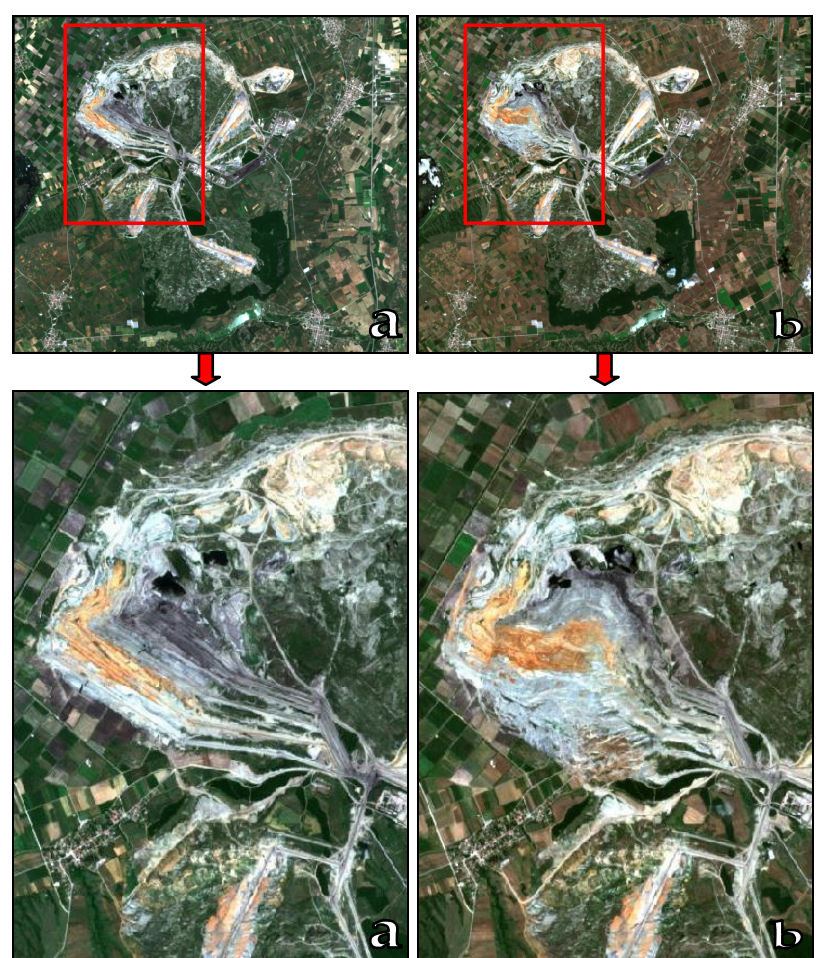

Figure 10. Sentinel-2A images of the study area in Natural Color Composite (4-3-2) before (a) and after (b) the landslide

Visual interpretation of Sentinel-2 images could prove to be more effective than interpretation of Landsat 8 images due to higher spatial resolution of the former ( 10 meters versus the 30 meters of Landsat-8). In addition, relevant indicators as texture, vegetation density, land use, cracks, surface disturbance or scarp visibility could be used to detect the presence of landslides. As shown in the second pair of images in Figure 10 the affected area is clearly detected and difference in texture as well as surface disturbance are also evident.

To exploit further the high spatial resolution that Sentinel-2 offers (10 $\mathrm{m}$ after resampling), as well as the processing level of the data (L2A data are atmospherically corrected) an image algebra change detection technique (image difference) was applied to detect spectral reflectance differences between the two images.

Image difference is an image-to-image comparison and can be used for change analysis with images that depict the same area at different points in time. This process computes the differences between two images, highlighting change that exceeds a user-specified threshold (ERDAS Field Guide, 2013). The first image (before the event) is subtracted from the second image (after the event). Any changes in brightness values over time are reflected in the resulted grayscale image. Selecting a threshold value to express the changes in brightness as a percent, increases or decreases in brightness values that are greater than this threshold will be highlighted in certain color. Familiarity with the study area could help to place the critical threshold properly between true changes and spurious changes. The final product is a thematic image.

The resulted thematic image after applying image difference in Sentinel-2A images is presented in Figure 11. The red color represents the changes detected in brightness values (increases 
or decreases) regarding the images that are compared (before and after the landslide). The processing was limited in an area of interest according to the previous findings (landslide area detection in the left part of the lignite mine).

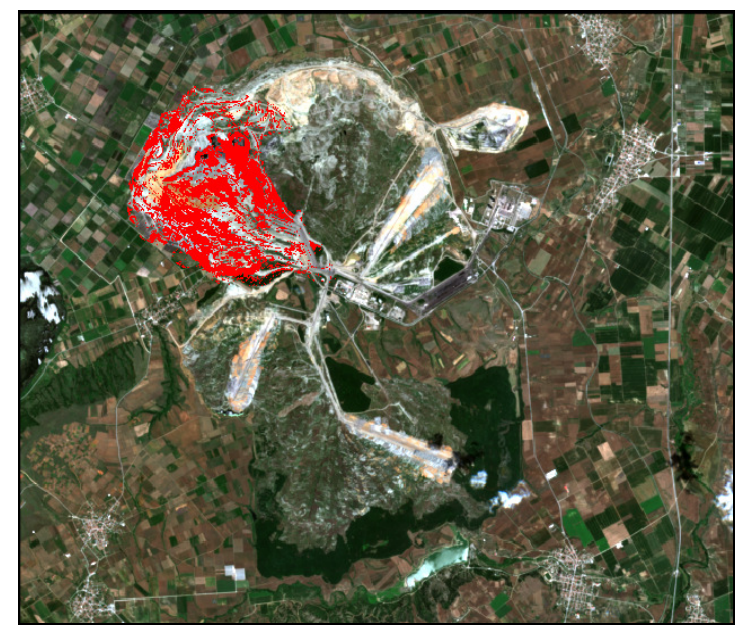

Figure 11. Resulted image after applying 'image difference'

\section{DISCUSSION - CONCLUSIONS}

Natural or man-made disasters are phenomena that can affect large areas and have many impacts (environmental, societal and economic). Landslides are among the major disasters of large scale that may affect the natural environment as well as urban areas, often causing massive destruction, loss of property, or even fatalities worldwide. Developing tools that are effective for disaster management is imperative to monitor and mitigate their effect. Satellite data and remote sensing techniques, combined with geological data and studies can provide valuable information regarding monitoring of natural hazards in general and especially of landslides.

In this paper Landsat 8 and Sentinel-2 satellite data were used to study a complex set of landslides that occurred in the lignite mine of Amynteon in north-western Greece. The landslide occurred in along the south faces of the mine, resulting to extended collapses, destruction of mining machinery, evacuation of the adjacent Anargyri village and a big financial impact. Digital image processing techniques were applied for change detection in satellite data acquired before and after the event and geological data were also used to provide information about the geological background of the area and landslides vulnerability.

According to geological data, this is probably a multifactor event. It is possible that the multifragmented Plio-Pleistocene sedimentary sequence, due to the transfer zone between the Anargyri and Vegora marginal fault zones acted as a soil, instead of a rock, mass. These fault zones affected the lignite bearing formations, causing poor cohesion. Due to widespread fragmentation of the lignite-bearing sequence the mine landslide shows characteristics of a rotational landslide. It is also possible that human factors affected the initiation of the landslide. Hydrogeological factors that predated the event had already been identified in previous studies (e.g. Tzampoglou and Loupasakis, 2016), while, a few days before the main landslide a heavy rainfall was recorded during a normally dry period, possibly accelerating the already initiated earth mass movements.
Regarding digital processing of Landsat 8 data, different color composites along with spectral enhancement (principal components analysis-PCA) were used to detect the changes and delineate the landslide. Spectral capabilities of the data gave the opportunity to identify the location, as well as the extent of the landslide. Applying PCA, data were compressed into fewer bands and the resulted images (first three components) were visually interpreted giving satisfactory results in change detection analysis.

In order to delineate the landslide area in more detail a Wavelet transform was applied to combine the rich spectral context of the multispectral images with the high spatial resolution of the panchromatic image (pan-sharpening). The pansharpened images were effectively evaluated visually, as well as quantitatively. They can be photointerpreted easier than the original, while preservation of the spectral characteristics makes them suitable for change detection.

Sentinel-2A satellite data were also used as they were considered effective for change detection analysis due to high spatial resolution (higher than this of Landsat 8 data, even after pan-sharpening), data acquisition frequency and policy of free data (as Landsat 8 data). Visual interpretation of Sentinel-2 images provides more details about the affected area as differences in texture and surface disturbance are clearly detected.

To exploit further the high spatial resolution of Sentinel-2 atmospherically corrected data (Level-2 products) an image algebra technique (image difference) was applied to detect spectral reflectance differences between the two images. The resulted thematic image that reflects changes in brightness values of the pixels provides useful information about the parts of the lignite mine that are affected and could contribute further to landslide monitoring. Direct digital processing for change detection may limit the uncertainty of outputs, as well as the subjectivity and the strict dependency on human expertise that visual interpretation introduces.

Further processing extension could include a combination of SAR and optical data. SAR data could be a further step in digital processing (displacement calculations and volume estimation), especially in scenes where cloud cover impedes optical acquisition. Moreover, terrestrial laser scanning (TLS) systems could be used to generate 3D point clouds and DEMs of the area contributing to landslide monitoring. Complementary ground-based techniques could also be used to acquire precise information on displacement or deformation at specific locations, especially near residential areas and road infrastructure.

\section{REFERENCES}

Chatzipetros, A., 1998, Palaeoseismological and morphotectonic study of the Mygdonia, Eastern Halkidiki and Kozani-Grevena active fault systems. PhD thesis. Aristotle University of Thessaloniki (in Greek).

Deng, J.S., Wang, K., Deng, Y.H., Qi, G.J., 2008. PCA-based land-use change detection and analysis using multitemporal and multisensor satellite data. International Journal of Remote Sensing, 29 (16), pp. 4823-4838. 
Dimitrakopoulos, D., Koumantakis, I., 2017. Hydrodynamic regime of Amynteon basin. Influence of open lignite mines. $11^{\text {th }}$ International Hydrogeological Congress of Greece. 4-6 October 2017, Athens, Greece.

ERDAS Field Guide ${ }^{\mathrm{TM}}$, Intergraph Corporation, Erdas Inc., U.S.A, 2013, pp. 440-445, 453-454.

Gungor, O., Shan, J. (2004). Evaluation of Satellite Image Fusion Using Wavelet Transform. XX th ISPRS Congress, Istanbul, Turkey.

Gupta, R.P., Tiwari, R.K., Saini, V., Srivastava, N., 2013. A Simplified Approach for Interpreting Principal Component Images. Advances in Remote Sensing, 2, pp. 111-119.

Hervás, J., Barredo, J.I., Rosin, P.L., Pasuto, A., Mantovani, F., Silvano, S., 2003. Monitoring landslides from optical remotely sensed imagery: The case history of Tessina landslide, Italy. Geomorphology, Vol. 54, pp. 63-75.

Joyce, K.E., Belliss, S.E., Samsonov, S.V., McNeill, S.J., Glassey, P.J., 2009. A review of the status of satellite remote sensing and image processing techniques for mapping natural hazards and disasters. Progress in Physical Geography, 33, pp. 183-207.

Karagianni, A., Lazaridou, M., 2017. Fusion of Multispectral and Panchromatic Satellite Images in Environmental Issues. International Journal of Engineering Research and Applications, 7 (7), pp. 47-50.

Kilias, A. and Mountrakis, D., 1989. The tectonic nappe of Pelagonian zone: Tectonics, metamorphism and magmatism. Bulletin of Geological Society of Greece, 23, pp. 29-46 (in Greek).

Mantovani, F., Soeters, R., Van Westen, C.J., 1996. Remote sensing techniques for landslide studies and hazard zonation in Europe. Geomorphology, 15, pp. 213-225.

Metternicht, G., Hurni, L., Gogu, R., 2005. Remote sensing of landslides: An analysis of the potential contribution to geospatial systems for hazard assessment in mountainous environments. Remote Sensing of Environment, 98, pp. 284303.

Mountrakis, D., 1986. The Pelagonian Zone in Greece: A Polyphase-Deformed Fragment of the Cimmerian Continent and Its Role in the Geotectonic Evolution of the Eastern Mediterranean. Journal of Geology, 94, pp. 335-347.

Pavlides, S., 1985. Neotectonic evolution of Florina Vegoritida - Ptolemais basin. PhD thesis. Aristotle University of Thessaloniki (in Greek).

Pavlides S. and Mountrakis, D., 1987. Extensional tectonics of northwestern Macedonia, Greece, since the Late Miocene. Journal of Structural Geology, 9, pp. 385-392.

Pavlides, S.B., Zouros, N.C., Chatzipetros, A.A., Kostopoulos, D.S. and Mountrakis D.M., 1995. The 13 May 1995 western Macedonia, Greece (Kozani-Grevena) earthquake; preliminary results, Terra Nova, 7, pp. 544-549.
Scaioni, M., Longoni, L., Melillo, V., Papini, M., 2014. Remote Sensing for Landslide Investigations: An Overview of Recent Achievements and Perspectives. Remote Sensing, 6, pp. 59095937.

Tzampoglou, P., Loupasakis, C., 2016. New data regarding the ground water level changes at the Amyntaio basin - Florina Prefecture, Greece. Bulletin of the Geological Society of Greece, 50, pp. 1006-1015.

Tzampoglou, P., Loupasakis, C., 2017a. Mining geohazards susceptibility and risk mapping: The case of the Amyntaio open-pit coal mine, West Macedonia, Greece. Environmental Earth Sciences, 76:542.

Tzampoglou, P., Loupasakis, C., 2017b. Updated ground water piezometry data of the Amyntaio sub-basin and their effect on the manifestation of the land subsidence phenomena. $11^{\text {th }}$ International Hydrogeological Congress of Greece. 4-6 October 2017, Athens, Greece.

Tzampoglou, P., Loupasakis, C., (in press). Evaluating geological and geotechnical data for the study of land subsidence phenomena at the perimeter of the Amyntaio coalmine, Greece. International Journal of Mining Science and Technology, DOI: 10.1016/ j.ijmst.2017.11.002.

van Westen, C., 2000. Remote Sensing for Natural Disaster Management, International Archives of Photogrammetry and Remote Sensing, Amsterdam, Netherlands, Vol. XXXIII, Part B7, pp. 1609-1617.

Zhang, Y., 2004. Understanding Image Fusion. Photogrammetric Engineering \& Remote Sensing, pp. 657-661.

Website: https://maps.google.com (last retrieved February 2018).

Website: https://pubs.usgs.gov (last retrieved February 2018).

Website: http://meteosearch.meteo.gr/data/amyntaio/2017-06.txt (last retrieved February 2018).

Website: http://landsat.usgs.gov/landsat8.php (last retrieved February 2018).

Website: http://earthexplorer.usgs.gov (last retrieved February 2018).

Website: https://earth.esa.int (last retrieved February 2018).

Website: https://sentinel.esa.int/web/sentinel/missions/sentinel2 (last retrieved February 2018).

Website: https://scihub.copernicus.eu (last retrieved February 2018). 